\title{
Cation exchange applications of synthetic tobermorite for the immobilization and solidification of cesium and strontium in cement matrix
}

\author{
O P SHRIVASTAVA* and RASHMI SHRIVASTAVA \\ Department of Chemistry, Dr HS Gour University, Sagar 470 003, India
}

MS received 15 May 2000; revised 16 August 2000

\begin{abstract}
Immobilization and solidification of hazardous cations like $\mathrm{Cs}^{137}$ and $\mathrm{Sr}^{90}$ are required while handling the radioactive waste of nuclear power plants. Efforts are on to find a fail proof method of safe disposal of nuclear wastes. In this context, various materials like borosilicate glass, zeolites, cements and synthetic rocks have been tried by several workers. This communication deals with the synthesis, characterization, cesium uptake capacity and leaching behaviour of synthetic alumina-substituted calcium silicate hydroxy hydrate, which are close to that obtained for the natural mineral, $11 \AA$ tobermorite. The synthetic mineral show cation selectivity for $\mathrm{Cs}^{+}$in presence of 500-1000 times concentrated solutions of $\mathrm{Na}^{+}, \mathrm{K}^{+}, \mathrm{Mg}^{2+}, \mathrm{Ca}^{2+}, \mathrm{Ba}^{2+}$ and $\mathrm{Sr}^{2+}$. Although the ordinary portland cement (OPC) which is often used in waste management operations alone holds negligible amounts of $\mathrm{Cs}^{+}$and $\mathrm{Sr}^{2+}$, the addition of alumina-substituted tobermorite to OPC enhances the retention power of cement matrix by drastically lowering the leach rate of cations.
\end{abstract}

Keywords. Cesium; strontium; selectivity; alumina substituted tobermorite; cement matrix.

\section{Introduction}

Solidification is one of the key technologies for removing hazardous wastes. The technique consists of entrapping the waste within a solid matrix having high structural integrity, so that the risk of leaching from the waste body is reduced to minimum (Plecas et al 1992). Radioactive waste is an unavoidable by-product in nuclear energy production (Plecas et al 1985). After volume reduction and valuable component recovery, waste materials have to be conditioned by cement for transport, storage and disposal. Conditioning is the waste management step in which radioactive waste is immobilized and packed. The objectives of immobilization are to convert the wastes into forms which are (i) leach resistant and impermeable, so that the release of radionuclides will be slow even though flowing water may contact them and (ii) mechanically, physically and chemically stable for handling, transport and disposal (Plecas et al 1985, 1991a). Many different types of glass and ceramic waste-forms have been studied over a long period of time. Some of the waste forms considered include borosilicate, aluminosilicate, high silica and phosphate glasses, silicate-based glass-ceramic, titaniabased crystalline ceramics, alumina-based ceramics, clay-based materials and various forms of cement and concrete. Waste forms have been examined in which the

\footnotetext{
*Author for correspondence
}

radionuclides and other waste elements are incorporated directly into the waste form lattice on an atomic scale as solid solutions. In addition, the wastes are incorporated macroscopically into a separate matrix phase, which may be either metallic or non-metallic to form a composite material. Keeping above points in view, calcium silicate hydroxy hydrate (tobermorite) may successfully be used as an additive with ordinary portland cement to reduce the leach rate of cesium and strontium. It is well known that cement has many characteristics in its favour: (i) it is a readily available material which is widely used in civil engineering, (ii) the raw material is cheap and processing equipment can be based on conventional technology, and (iii) the resulting (cement + additive) blocks have good mechanical properties. They are noncombustible, radiation resistant, chemically stable and moderately resistant to the release of radionuclides (Plecas et al 1991b, c, 1995). Additives like vermiculite, fly ash, different types of slags, sodium silicate, polymer etc are incorporated at the manufacturing or application stage as property modifiers in improved blended cement formulations (Gandhi 1997).

\section{Experimental}

The material was synthesized from lime, silica and alumina by the hydrothermal method described elsewhere (Kalousek 1957; Shrivastava and Rashmi 1998). The 
product was characterized by chemical analysis and powder X-ray diffraction in the range $2 \theta=5-80$. The morphology of the specimen was also examined under electron microscope (Phillips 420 TEM). The cesium uptake experiment had been carried out as follows: $25 \mathrm{mg}$ of sample was mixed with $75 \mathrm{mg}$ of OPC, and this $1: 3$ ratio was maintained because on increasing the additive more than $33 \%$ the block starts losing their mechanical strength. The mixing of additive and OPC was conducted in dry state in mortar pestle followed by homogenization using ethanol. The mixture was then equilibrated with $25 \mathrm{ml}$ of mixed aqueous solution containing $5 \times 10^{-4} \mathrm{~N} \mathrm{Cs}^{+}$and $0 \cdot 1 \mathrm{~N}$ of $\mathrm{M}^{n+}$ (where $\mathrm{M}^{n+}=\mathrm{Na}^{+}, \mathrm{K}^{+}, \mathrm{Mg}^{2+}, \mathrm{Ca}^{2+}, \mathrm{Ba}^{2+}$ and $\mathrm{Sr}^{2+}$ ) ions, by using appropriate amounts of $0.0005 \mathrm{~N}$ $\mathrm{CsCl}+0 \cdot 1 \mathrm{~N} \quad \mathrm{NaNO}_{3}, \quad 0 \cdot 0005 \mathrm{~N} \quad \mathrm{CsCl}+0 \cdot 1 \mathrm{~N} \quad \mathrm{KNO}_{3}$, $0.0005 \mathrm{~N} \quad \mathrm{CsCl}+0.1 \mathrm{~N} \quad \mathrm{Mg}\left(\mathrm{NO}_{3}\right)_{2}, \quad 0.0005 \mathrm{~N} \mathrm{CsCl}+$ $0.1 \mathrm{~N} \mathrm{Ca}\left(\mathrm{NO}_{3}\right)_{2}, \quad 0.0005 \mathrm{~N} \quad \mathrm{CsCl}+0.1 \mathrm{~N} \quad \mathrm{Ba}\left(\mathrm{NO}_{3}\right)_{2}$, $0 \cdot 0005 \mathrm{~N} \mathrm{CsCl}+0 \cdot 1 \mathrm{~N} \mathrm{Sr}\left(\mathrm{NO}_{3}\right)_{2}$. $\mathrm{pH}$ of the mixed solution was about $7 \cdot 15$. The ionic strength for $1: 1$ and $1: 2$ ionic solutions were $0 \cdot 1005$ and $0 \cdot 3005$, respectively. Leach rate studies were performed using standard method (Hespe 1971). The general procedures adopted are given below.

(I) The 10, 20, 30 and $40 \%$ blocks each of similar dimensions $(\mathrm{ht}=1.2 \mathrm{~cm}, \mathrm{r}=0.5 \mathrm{~cm}$ ) were prepared by adding $90,80,70$ and $60 \%$ of OPC to $14.4 \mathrm{wt} \%$ aluminasubstituted tobermorite. The contents were thoroughly mixed in mortar pestle keeping total solid/water ratio $=$ $0 \cdot 6$. This was later cured for 28 days in $100 \%$ relative humidity. The geometrical surface area of each cylindrical block was measured manually.

(II) Sealed polythene bottles were used as leachant containers.

(III) The leachant was $25 \mathrm{ml}$ of distilled water at $25^{\circ} \mathrm{C}$, renewed at each sampling. The sampling was done daily for the first week, weekly for three weeks and fortnightly for the rest of the period.
$\mathrm{Cs}^{+}$and $\mathrm{Sr}^{2+}$ analyses have been carried out on GBC 902D/B double beam atomic absorption spectrophotometer. Each experiment was performed in duplicate to record the final concentration change.

\section{Results and discussion}

X-ray powder pattern of the hydrothermally synthesized title phase $\mathrm{Ca}_{5}(\mathrm{OH})_{2} \mathrm{Al}_{x} \mathrm{Si}_{6-x} \mathrm{O}_{16} \cdot 4 \mathrm{H}_{2} \mathrm{O}$ matches in intensity and position with the JCPDS file (JCPDS 1989). It gives 22 reflections with ' $d$ ' values between 11.3 and $1 \cdot 15 \AA$ (figure 1). Figures 2 and 3 compare the lattice expansion of cesium exchanged phase with that of the synthetic alumina-substituted tobermorite. The powder pattern of the tobermorite loaded OPC shows largely a mixed pattern of crystalline and amorphous phase of both OPC and additive with lower intensity. The pattern of the mixture shows that the powder mix of OPC and tobermorite retains the tobermorite structure intact. However, the X-ray diffraction pattern of the blocks shows the presence of 'ettrignite' along with highly disordered or even amorphous phases of other calcium silicate hydrates (Vlachou and Piau 1997, 1998). The scanning electron micrographs of the material show aggregate of lath like crystallites, which are $0 \cdot 2-5 \cdot 0 \mu \mathrm{m}$ long and $0 \cdot 2-1 \mu \mathrm{m}$ wide (figure $4 \mathrm{a}$ ). Cesium loaded tobermorite shows the change in shape of crystallites from plate like to lath like. The size of the crystal after cesium uptake remains same as seen in figure $4 \mathrm{~b}$. The typical lath like and plate like morphology of tobermorites is a function of the extent of Al-substitution and an inverse relationship between particle size and extent of Al-substitution has been confirmed (Komarneni and Tsuji 1989a).

Table 1 shows the data on selective uptake of the $\mathrm{Cs}^{+}$ from mixed cationic solution. The cesium sorption properties of the material may be attributed to the crystallo-

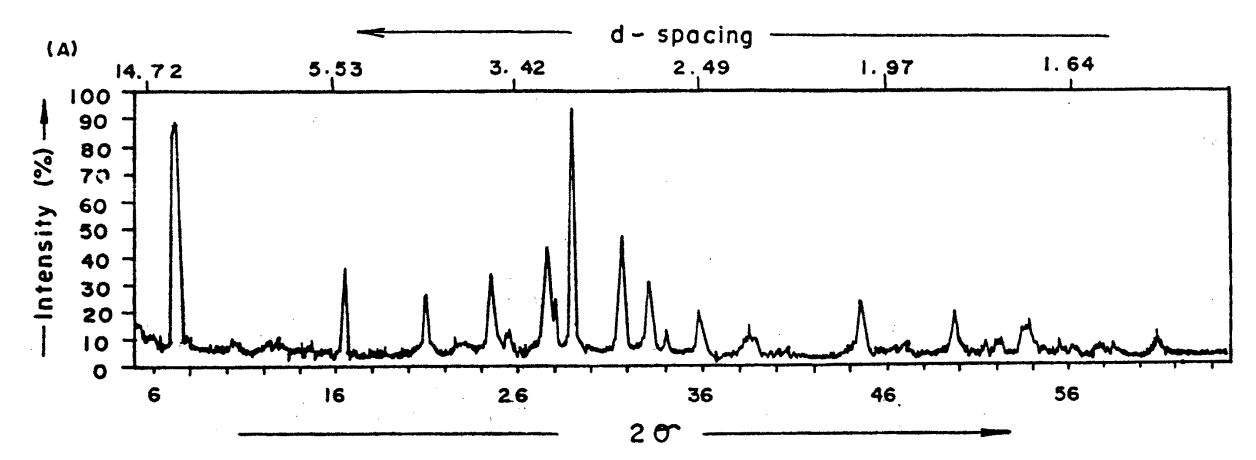

(B) CALCIUM SILICATE HYDROXIDE HYDRATE/TOBERMORITE - IIA (SYNTH)

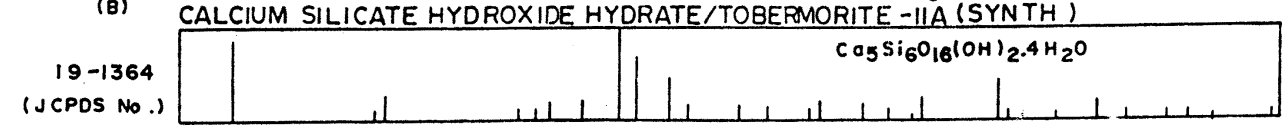

Figure 1. X-ray powder diffraction pattern of synthetic unsubstituted $11 \AA$ tobermorite: (A) XRD pattern of synthetic sample and (B) JCPDS profile. 


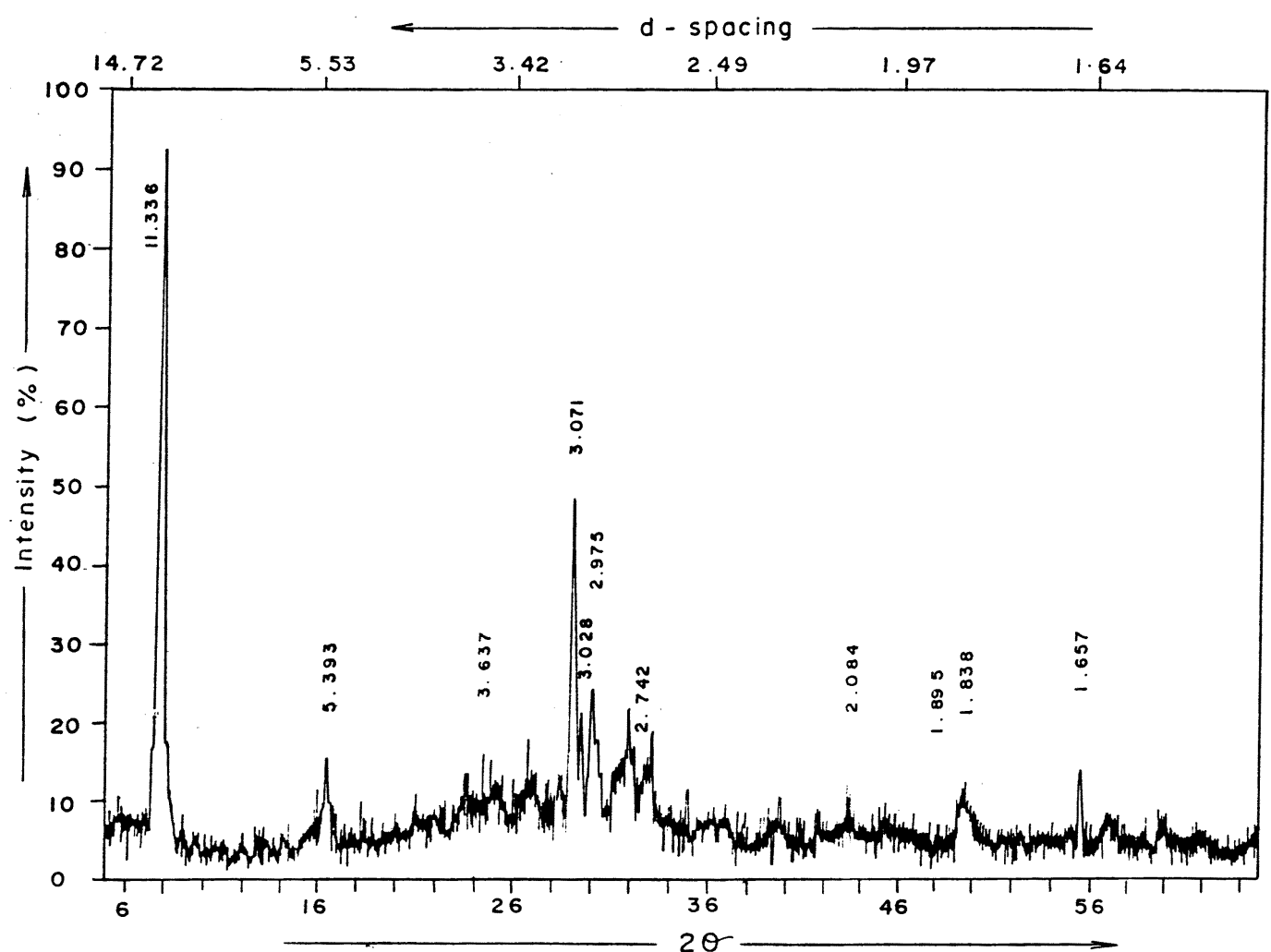

Figure 2. X-ray powder diffraction pattern of synthetic $10 \cdot 0$ mole\% Al-substituted tobermorite.

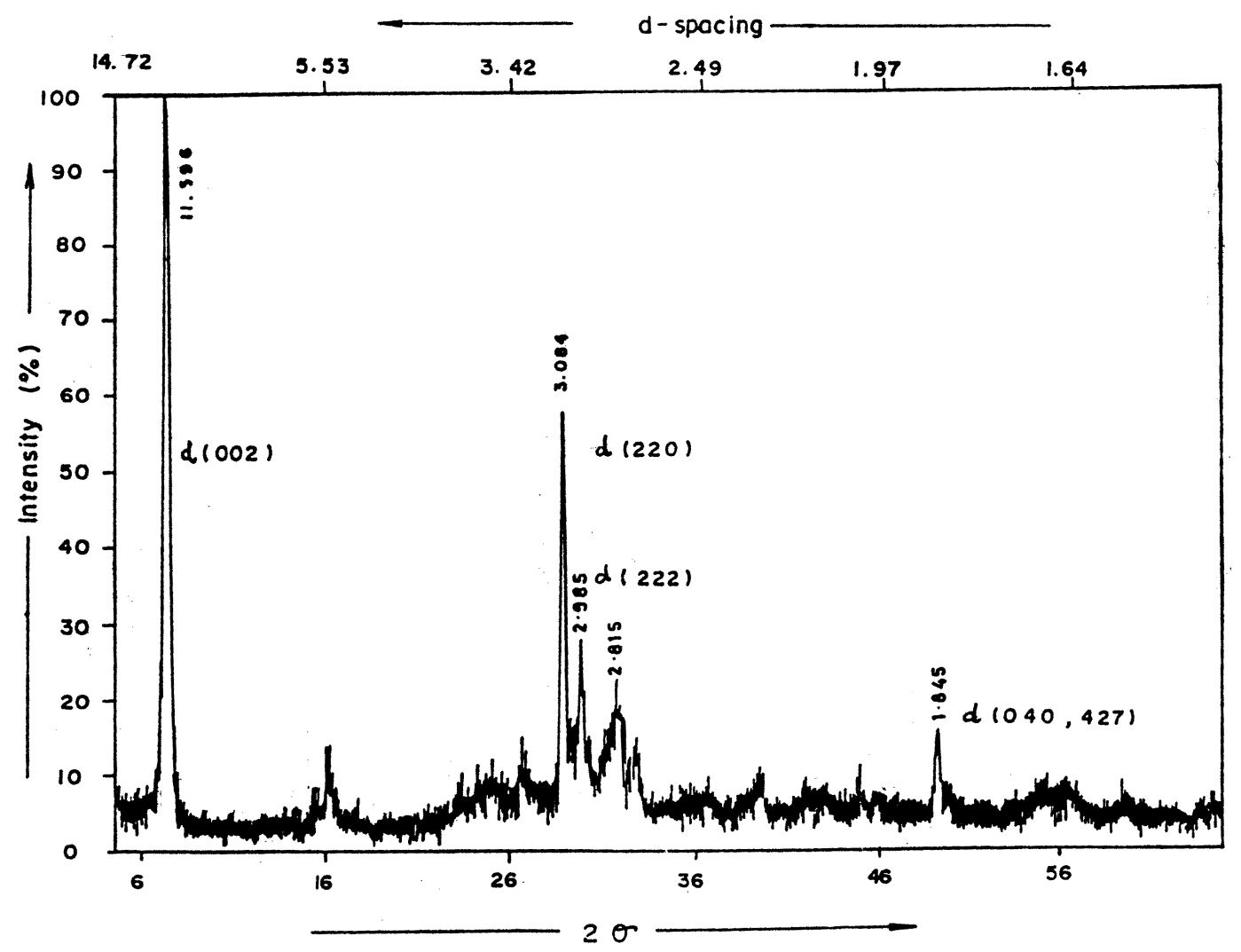

Figure 3. X-ray powder diffraction pattern of $\mathrm{Cs}^{+}$-exchanged $10 \cdot 0 \%$ Al-substituted tobermorite. 
chemical incorporation of cesium in layered lattice framework of tobermorite (Komarneni and Roy 1983). The cesium fixation in the layered lattice framework of the tobermorite is also confirmed by the expansion of $d$ spacing from 11.336 to $11.596 \AA$. The uptake in tobermorite is partly due to the breaking of bonds from planar and edge surface sites of the layered lattice (Komarneni and Tsuji 1989a). It has also been observed that the $\mathrm{Cs}^{+}$ removal decreases in the presence of larger cations like $\mathrm{K}^{+}$and $\mathrm{Ba}^{2+}$ whereas, in presence of other smaller cations like $\mathrm{Na}^{+}, \mathrm{Ca}^{2+}$ and $\mathrm{Mg}^{2+}$ the selective property of tobermorite is significantly retained (Komarneni and Tsuji 1989b; Shrivastava and Verma 1995b; Shrivastava et al 1995). The alkali metal ions have been found to lie in the sequence $\mathrm{Li}^{+}>\mathrm{Na}^{+}>\mathrm{K}^{+}$with respect to their tolerance of $\mathrm{Cs}^{+}$uptake onto synthetic tobermorite, indicating that $\mathrm{K}^{+}$ causes the maximum hindrance in $\mathrm{Cs}^{+}$uptake. The blocking action appears to be a function of cation size. Similarly the selectivity sequence for alkaline earth metal ions exist as $\mathrm{Mg}^{2+}>\mathrm{Ca}^{2+} \gg \mathrm{Ba}^{2+}$. The ion exchange remains selective for $\mathrm{Cs}^{+}$even in the presence of 500-1000 times

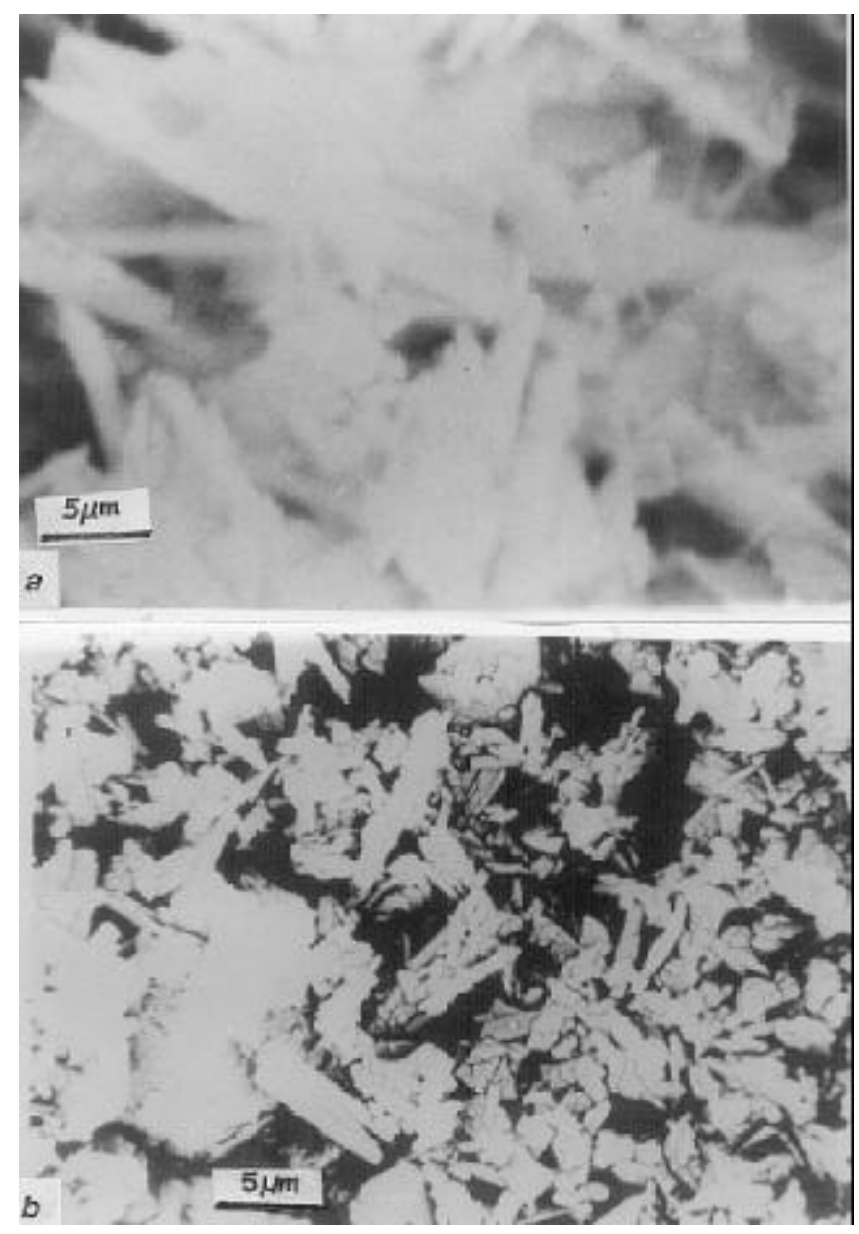

Figure 4. Scanning electron micrographs of a. aluminasubstituted tobermorite and b. Cs loaded alumina-substituted tobermorite. higher concentration of the competing metal ions $\left(\mathrm{Na}^{+}\right.$, $\mathrm{K}^{+}, \mathrm{Mg}^{2+}, \mathrm{Ca}^{2+}, \mathrm{Ba}^{2+}$ and $\mathrm{Sr}^{2+}$ ).

Figure 5 shows the leaching curve obtained by plotting the cumulative leach fraction $(\Sigma A n / A o) /(S / V)$ vs leach time, $t$, where, $\Sigma A n$ is the sum of the $\mathrm{Cs}^{+}(\mu \mathrm{g} / \mathrm{ml})$ released in all leaching periods up to time $t, A o$ the initial $\mathrm{Cs}^{+}$ $(\mu \mathrm{g} / \mathrm{ml})$ present in the block, $V$ the volume of the block, $S$ the surface area of the block and $t$ the time (days). It is clear from figure 5 that, as compared to $100 \%$ OPC block,

Table 1. Selective sorption of $\mathrm{Cs}^{+}$onto $1: 3$ mixture of tobermorite + OPC in presence of strong solution of competing cations.

\begin{tabular}{lccc}
\hline $\begin{array}{l}\text { Ion pair } \\
{\left[\mathrm{M}^{n+}+\mathrm{Cs}^{+}\right]}\end{array}$ & $\begin{array}{c}\text { Initial Cs} \\
(\mu \mathrm{g} / \mathrm{ml})\end{array}$ & $\begin{array}{c}\Delta \\
(\mu \mathrm{g} / \mathrm{ml})\end{array}$ & $\%$ Cs removal \\
\hline $\mathrm{Na}+\mathrm{Cs}$ & $39 \cdot 8$ & $14 \cdot 6$ & $36 \cdot 70$ \\
$\mathrm{~K}+\mathrm{Cs}$ & $12 \cdot 4$ & nil & nil \\
$\mathrm{Mg}+\mathrm{Cs}$ & $9 \cdot 6$ & $1 \cdot 8$ & $18 \cdot 75$ \\
$\mathrm{Ca}+\mathrm{Cs}$ & $6 \cdot 4$ & $6 \cdot 4$ & $76 \cdot 19$ \\
$\mathrm{Ba}+\mathrm{Cs}$ & $8 \cdot 0$ & $5 \cdot 0$ & $62 \cdot 50$ \\
$\mathrm{Sr}+\mathrm{Cs}$ & $8 \cdot 2$ & $5 \cdot 6$ & $68 \cdot 29$ \\
\hline
\end{tabular}

Wt. of exch. $=25 \mathrm{mg}$; wt. of $\mathrm{OPC}=75 \mathrm{mg}$; vol. of soln. $=$ $25 \mathrm{ml}$;

Normality of cations $=0.1 \mathrm{~N} \mathrm{M}^{n+}+0.0005 \mathrm{~N} \mathrm{Cs}^{+}\left[\mathrm{M}^{n+}=\mathrm{Na}^{+}\right.$, $\mathrm{K}^{+}, \mathrm{Mg}^{2+}, \mathrm{Ca}^{2+}, \mathrm{Ba}^{2+}$, and $\left.\mathrm{Sr}^{2+}\right]$.

Equilibration time $=7$ days, $\mathrm{pH}=7 \cdot 15$.

$\Delta=$ Initial concn. $\mathrm{Cs}^{+}$, final concn. $\mathrm{Cs}^{+}$.

$\%$ Cs removal $=\frac{\Delta \times 100}{\text { Initial Cs concn. }}$.

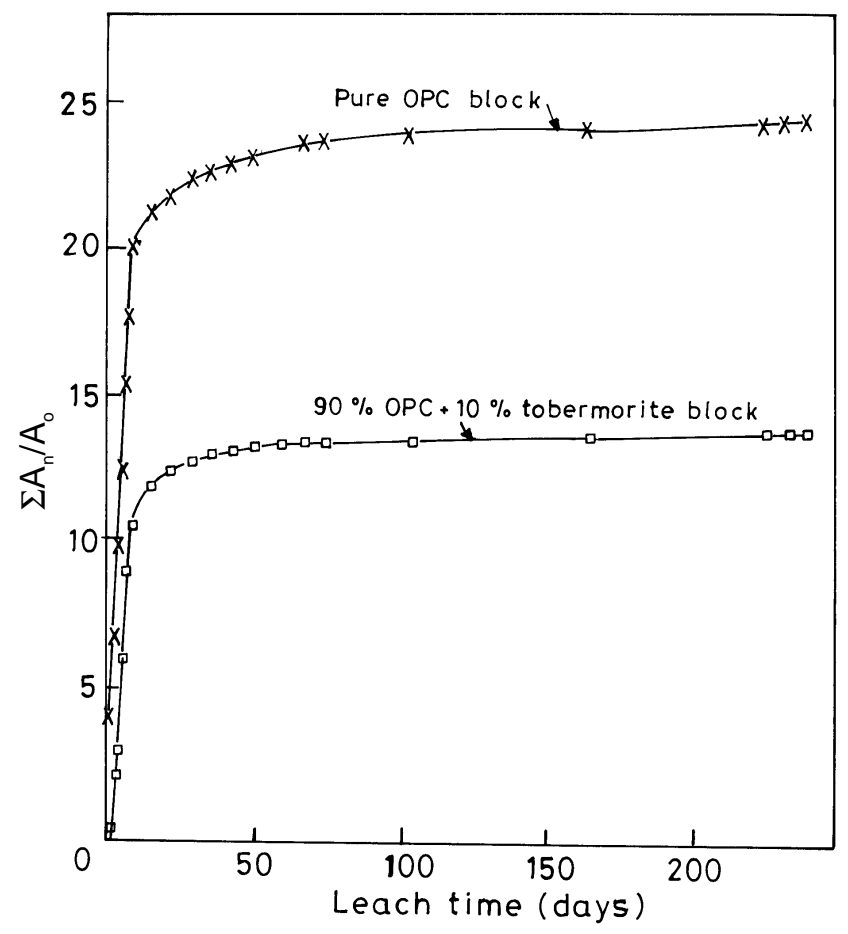

Figure 5. Cesium leach rate profile of $10 \%$ block of $14.4 \mathrm{wt} \%$ alumina-substituted tobermorite in ILW. 
the block prepared by adding $10 \%$ tobermorite and mixing it with simulated intermediate level waste (ILW), the cumulative fraction leach rate decreases by a factor of 10 , thus indicating that OPC mixed additive can be effectively used to separate $\mathrm{Cs}^{+}$from ILW (Shrivastava et al 1994). The composition of ILW simulate is as follows $(\mathrm{g} / \mathrm{l})$. $\mathrm{Na}^{+}=114 \cdot 17, \mathrm{Fe}^{3+}=0 \cdot 025, \mathrm{Al}^{3+}=9.98, \mathrm{OH}^{-}=21 \cdot 22, \mathrm{NO}_{2}^{-}$ $=4 \cdot 80, \quad \mathrm{NO}_{3}^{-}=160 \cdot 20, \quad \mathrm{CO}_{3}^{2-}=6 \cdot 24, \quad \mathrm{Cs}^{+}=0 \cdot 01, \quad \mathrm{Sr}^{2+}$ $=0.01, \mathrm{UO}_{2}^{2+}$ in trace amounts (sp. gravity $\left.1 \cdot 19\right)$. The calculated quantities of corresponding water soluble salts were mixed to adjust the composition in $\mathrm{g} / \mathrm{l}$ (Wattal et al 1989).

Figure 6 shows a comprehensive data profile obtained from five test blocks. The reference block contains only OPC whereas, the other four-test specimen are prepared from the additive and OPC in four different proportions $(10,20,30$ and 40). The mixing of the synthetic aluminasubstituted calcium silicate hydroxy hydrate along with OPC increases its $\mathrm{Sr}^{2+}$ retention power while OPC alone shows poor uptake of $\mathrm{Sr}^{2+}$. This is demonstrated by the study of leach rate data on the five different blocks. Leach rates (LR) were calculated using the Hespe formula:

$$
\mathrm{LR}=\text { l.w/c.t.s. }
$$

where, $l$ is the quantity of ion in leach solution $(\mu \mathrm{g} / \mathrm{ml})$, $c$ the quantity of ion left in solid block $(\mu \mathrm{g} / \mathrm{ml}), w$ the wt. of block $(\mathrm{g}), t$ the time of leach (days), and $s$ the surface area of the test specimen $\left(\mathrm{cm}^{2}\right)$. Leach rates expressed as $\mathrm{g} \mathrm{cm}^{-2} \mathrm{day}^{-1}$ on log scale were plotted against leach time in days. The entire leaching period can be broadly divided into three regions. Region I from 1 to 7 days, region II from 8 to 50 days and region III from 51 to 90 days. Region I shows the initial leaching within first 7 days, i.e. leaching from superficial surfaces of the block. Region II shows that after initial leaching within first seven days, there is a drastic reduction in release of $\mathrm{Sr}^{2+}$ ions from the blocks which is maintained over a longer period of time (50 days). In region III the leach rates are further lowered to $10^{-5}$ to $10^{-6} \mathrm{~g} / \mathrm{cm}^{2}$ days. This trend continues up to 90 days. The leach behaviour of the blocks can be explained as a combination of the two processes: (i) surface wash-off mechanism and (ii) diffusion stage mechanism. Region I shows the maximum leaching of the $\mathrm{Sr}^{2+}$ ions because of surface wash-off process. In this process a rapid equilibrium is established between ionic species present in the surface pores of the portland cement block and ions in the leachant solution. When all the $\mathrm{Sr}^{2+}$ has been leached out from the surface of the block, the $\mathrm{Sr}^{2+}$ ions migrate by longer pathways from the bulk (Crawford et al 1985). It is this diffusion-controlled stage which determines the long term leaching behaviour of the block. The final analysis of the post leached blocks have shown that strontium content appears to be permanently fixed in cement matrix. Analysis of the post leached block shows that up to a maximum of $38.20 \mathrm{meq}$ of $\mathrm{Sr}^{2+} / 100 \mathrm{~g}$ could be fixed in

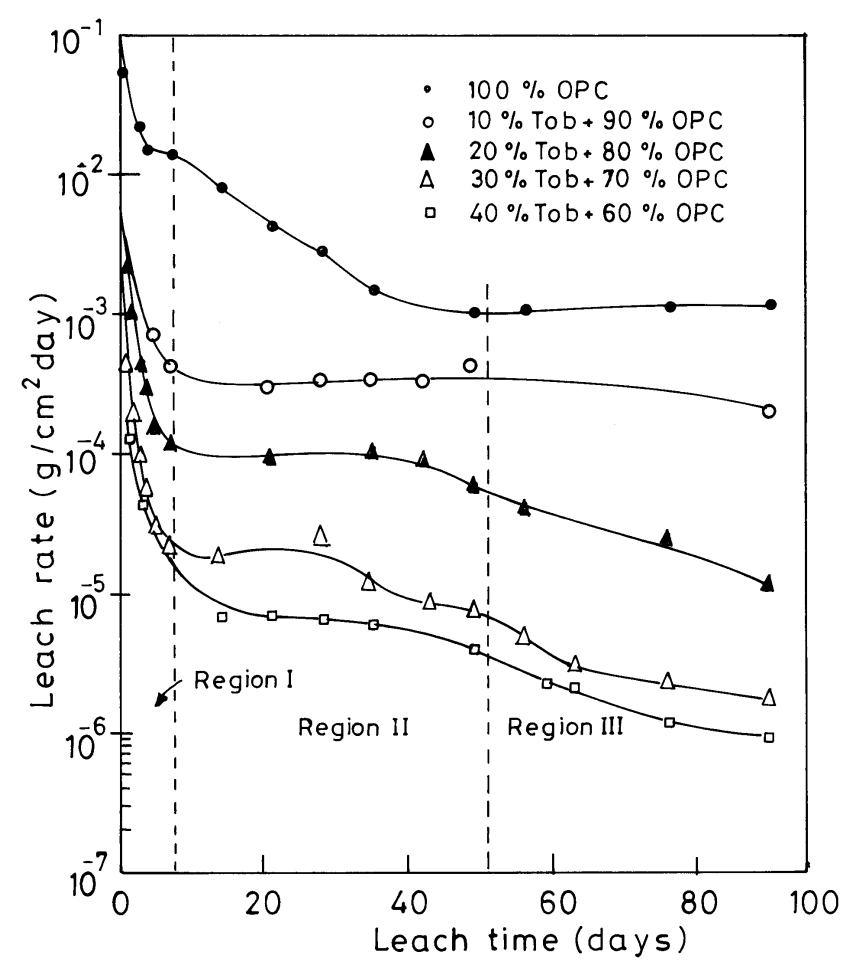

Figure 6. Leach rate profile of $\mathrm{Sr}^{2+}$ from $\mathrm{OPC}+14.4 \mathrm{wt} \%$ alumina-substituted tobermorite.

the blocks. It may be concluded from the data that (i) the synthetic phase of alumina-substituted tobermorite could be used for decontamination of radioactive Cs and $\mathrm{Sr}$ containing waste effluent, (ii) the title phase acts as an additive to OPC without degrading its mechanical strength and other properties and (iii) that the long-term leach rate of cesium and strontium from OPC can be drastically reduced by addition of $\approx 14.4$ wt. $\%$ of alumina substituted tobermorite in appropriate quantity.

\section{Acknowledgements}

We thank the Head, Department of Chemistry, Dr HS Gour University, Sagar for providing laboratory facilities and Dr J P Shrivastava, Department of Geology, Delhi University, for XRD data. We also thank CSIR, New Delhi for the award of a research associateship to one of us (RS).

\section{References}

Crawford R W, Glasser F P, Rahman A A, Angus M J and McCulloch C E 1971 Radioactive waste management and development of waste 6195

Gandhi P M 1997 Indian Association of Nuclear Chemists and Allied Scientists Bulletin 1132

Joint Committee on Powder Diffraction Standards (JCPDS) 1989 Card No. 19-1364, 29-379, Newton Square, Pennsylvania, USA 
Hespe E D 1971 Atomic Energy Rev. 9195

Kalousek G L 1957 J. Am. Ceram. Soc. 4074

Komarneni S and Roy D M 1983 Science 221647

Komarneni S and Tsuji M 1989a J. Am. Ceram. Soc. 721967

Komarneni S and Tsuji M 1989b J. Mater. Sci. 4698

Plecas I B 1983 Proc. waste management '83' (Tucson, Arizona) p. 186

Plecas I B, Mihajlovic L J and Kostadinovic A M 1985 RWMAD 6161

Plecas I B, Peric A D, Drijaca J D and Kostadinovic A M 1991a Cem. Concr. Res. 21941

Plecas I B, Peric A D, Drijaca J D and Kostadinovic A M 1991b J. Radioanal. Nucl. Chem. Lett. 154309

Plecas I B, Peric A D, Drijaca J D and Kostadinovic A M 1991c J. Radioanal. Nucl. Chem. Lett. 154121

Plecas I B, Peric A D, Glodic S D and Kostadinovic A M 1992 J. Radioanal. Nucl. Chem. Lett. 166373

Plecas I B, Peric A D, Drijaca J D and Kostadinovic A M 1995 J. Radioanal. Nucl. Chem. Lett. 199405
Shrivastava O P and Verma T 1995 J. advanced cement based matrices (New York: Elsevier Sci.) 2 p. 119

Shrivastava O P and Rashmi Shrivastava 1998 Indian J. Chem. 37(A) 726

Shrivastava O P and Rashmi Shrivastava 1999 Nuclear and radiochemistry symposium, BRNS, Department of Atomic Energy, BARC, Mumbai 3371

Shrivastava O P, Verma T and Shrivastava Rashmi 1994 Cation exchange applications of synthetic silicate minerals for immobilization and solidification of simulated nuclear waste in cement matrix, DAE Project Report No. 36/3/91-G p. 117

Shrivastava O P, Verma T and Wattal P K 1995 J. advanced cement based matrices (New York: Elsevier Sci.) 2 p. 80

Vlachou P V and Piau J M 1997 Cem. Concr. Res. 2869

Vlachou P V and Piau J M 1998 Cem. Concr. Res. 2928

Wattal P K, Govindan A K, Jahagirdar P B and Chitnis R R 1989 Evaluation of matrices and conditioning techniques for low and intermediate level waste concentrations and residue, PE and SDD, BARC AEC Govt of India 